\title{
Uptake of Hormonal Implants Contraceptive in Zaria, Northern Nigeria
}

\author{
N. H. Madugu*, M. A. Abdul, U. Bawa, B. Kolawole \\ Department of Obstetrics and Gynaecology, Ahmadu Bello University Teaching Hospital, Zaria, Nigeria \\ Email: ${ }^{*}$ madugu20007@yahoo.com
}

Received 9 April 2015; accepted 20 May 2015; published 25 May 2015

Copyright (C) 2015 by authors and Scientific Research Publishing Inc.

This work is licensed under the Creative Commons Attribution International License (CC BY). http://creativecommons.org/licenses/by/4.0/

(c) (i) Open Access

\begin{abstract}
Objective: To document our experience on the use of Jadelle/Implanon contraceptives that was recently introduced into Ahmadu Bello University Teaching Hospital (ABUTH), Zaria, Nigeria. It is pertinent to generate data on the experiences in the use of this contraceptive in a cross sectional study within Zaria, Northern Nigeria. Method: Data on consecutive clients that accepted Jadelle/ Implanon from June 2009 to November 2013 at ABUTH were extracted from their cards and analyzed using SPSS version 17. Out of a total of 11,502 clients that were for contraception during the period under review, 798 accepted Jadelle/Implanon accounting for $7 \%$ of the total clients. All the clients were married. About $67.8 \%$ were Muslims while $27.2 \%$ were Christians and $5 \%$ belong to other sect. $4140(36 \%)$ had tertiary education. Most of the client has been on one form of modern contraception; only $16 \%$ were first time users who accepted implant after counselling. $37 \%$ of the clients are full time housewives. The discontinuation rate was found to be $26 \%$ for Jadelle and $19 \%$ for Implanon. No pregnancy was recorded during this period. Conclusion: Jadelle/Implanon account for $\mathbf{7 \%}$ of contractive uptake and a high discontinuation rate was found among the users.
\end{abstract}

\section{Keywords}

Jadelle/Implanon, Contraceptives, Implant, Family Planning

\section{Introduction}

Contraceptive implants are one of the most effective family planning methods available and well-accepted worldwide [1] [2]. They are long term hormonal contraceptive implants and a better option for women in sub-Saharan Africa due to its effectiveness and convenience [3] [4]. Jadelle is a set of two flexible cylindrical implants, each consisting 75 micrograms of progestin-levonorgestrel while the Implanon contains 68 micro-

\footnotetext{
"Corresponding author.
} 
grams of Etonogestrel [5]. They are sealed with adhesive, sterilized and inserted in a superficial plane beneath the skin of the upper arm under aseptic condition and can be effective for five years in the case of Jadelle but three years for Implanon [6] [7].

Unlike other hormonal delivery systems, they do not cause unnecessary peaks in progestin levels and do not use estrogens, and thus their health risks are minimal [8] [9]. Side effects are minor but often bothersome, causing some discontinuation of the method. They offer some advantages such as being less conspicuous and easier to insert and remove [4]. Some women also like that pelvic exams and laboratory tests are not required and that implants can be used discreetly. Furthermore, implants do not interfere with sexual intercourse, and return to fertility upon removal is not delayed or negatively affected [6].

These implants have become popular and in high demand in many countries including sub-Saharan Africa where family planning programs are available [3] [6] [10]. However offering them as a contraceptive choice requires that trained practitioners perform the minor procedures necessary to either insert or remove the device sub dermal, in a reliably aseptic environment [5]. The lack of trained personnel in some remote area to offer this service makes the service assessable to some women who would have benefited from it. It is only if the patient has no contraindication to progestin only contraception and no allergy to the use of antiseptic or the local anesthetic drug to be used that the implant can be inserted according to the recommended procedure [11]. Specific counseling should also be made available to potential recipients by trained counsellor in contraceptive services, so that the clients clearly understand implant insertion and removal procedures, the risks and benefits of implant use, as well as what to expect in terms of side effects, particularly menstrual bleeding changes.

Jadelle and Implanon were introduced into Nigeria in 2006 by Federal Ministry of Health and by January 2007, the Reproductive Health Center Ahmadu Bello University Teaching Hospital (our center) commenced offering the services. The aim of this study is to document our experience in the use of Jadelle and Implanon implants in our center (located in North Western Nigeria) focusing on the uptake rate, side effects profile and the discontinuation rate of the implants.

\section{Materials and Methods}

A cross sectional study was conducted involving reviewing all the case files of the clients that came for family planning services from June 2009 to November 2013 at the Reproductive Health Center of the Ahmadu Bello University Teaching Hospital Zaria. A total of 11,502 clients presented for family planning services within this period under review. The cards of all the clients seeking family planning service within this were obtained after permission was sought and information on maternal age, parity, religion, level of education, previous history of contraception, marital status and source of information. The side effect of chosen contraceptive, continuation and reason for discontinuation were also included.

The records also shows that trained counselors would have counseled all the clients on the various broad mix of contraceptive; their contraindication, side effect, possible complications and medical eligibility criteria were duly discussed with these clients. Those who consented for implants further had method specific counselling immediately before the insertion, where the details of insertion and removal technique were discussed. Possible side effect and complications of the chosen method were also discussed. Data on consecutive clients relating to the above variables among those that accepted Jadelle/Implanon were analyzed using SPSS17.

\section{Results and Discussion}

\subsection{Results}

During the period under review, there were Eleven thousand five hundred and two $(11,502)$ clients who were counseled and accepted broad mix of contraceptives available. Six hundred and seventy seven (677) clients accepted Jadelle (5.9\%) and one hundred and twenty one (121) accepted Implanon (1.1\%) both accounting for 7\% uptake of the broad mix at Ahmadu Bello University Teaching Hospital, Zaria.

The socio-demographic profiles of client are shown in Tables 1-3. The age of the client ranges from $31.4+/-$ 6.2 years, the largest number of clients' falls into the age 36 - 40 groups, with a total of 3795 (33\%). Seven thousand one hundred and eighty eight (62.5\%) of the study group was below 36years of age.

Table 2 shows the distribution of client by level of education and only 21\% had tertiary education. Four thousand one hundred and forty (36\%) who were the majority had only Primary education. 
Table 1. Percentage distribution of client by Age.

\begin{tabular}{ccc}
\hline Age (yrs) & No. & $\%$ \\
\hline $16-20$ & 863 & 7.5 \\
$21-25$ & 1035 & 9.0 \\
$26-30$ & 3105 & 27.0 \\
$31-35$ & 2185 & 19.0 \\
$36-40$ & 3795 & 33.0 \\
$>40$ & 518 & 4.5 \\
\hline
\end{tabular}

Table 2. Percentage distribution of client by level of education.

\begin{tabular}{ccc}
\hline Level education & No. & $\%$ \\
\hline Primary & 4140 & 36 \\
Secondary & 2419 & 21 \\
Tertiary & 3105 & 27 \\
Non-formal & 1840 & 16 \\
\hline
\end{tabular}

Table 3. Percentage distribution client by religion.

\begin{tabular}{cc}
\hline Religion & No. \\
\hline Muslims & 67.8 \\
Christians & 27.2 \\
Others & 5.0 \\
\hline
\end{tabular}

Parity distribution of the client indicates that six thousand three hundred and twenty two (55\%) have been pregnant at least two times with a mean parity $2.9+/-1.8$. Among these clients mean number of living children $2.7+/-1.6$ and two thousand and seventy (18\%) had been pregnant for at least 10 times (Table 3). All the clients were married (Table 4) 67.8\% were Muslims while 27.2\% were Christians and 5\% of the group belongs to other religious sect (Table 5).

None of the client experienced any complication during insertion and removal and there was no pregnancy recorded within the period under review. Most of the users has had counseling and used a form of contraception including hormonal. There was an average weight gain of $1.9 \mathrm{~kg}$. The discontinuation rate for the implants was found to be $26.6 \%$ for Jadelle and $19.8 \%$ for Implanon (Table 5).

\subsection{Discussion}

Our study shows that the uptake of implants at ABUTH Zaria as a percentage method mix was low 7\%. In Jos, North-central Nigeria the uptake was 13.4\% [12], while Abia, South Eastern Nigeria, was 6.9\%. In Port-Harcourt South-South Nigeria the uptake rate was $0.95 \%$ [4]. In Table 1, an average age distribution fall with the 31 - 35 years of age, however the highest frequency was within the age group of 36 - 40 years. While Table 2 shows that those with primary education (36\%) visited the family planning clinic than any other group based on their level of education.

Menstrual problems are the main reason why women discontinue Norplant and still remains the reason for these modern implants despite researches carried out indicating that reduced number of implanted units and introduction of other progestin's may minimize this side effects. Northern Nigeria is predominantly made up of Muslims and this study we had $67.8 \%$ which is almost two third of the population under review.

Report also in Nigeria revealed that menstrual irregularity is not only the commonest side effects but also the 
Table 4. Percentage distribution of client by parity.

\begin{tabular}{ccc}
\hline Parity & No. & $\%$ \\
\hline 1 & 690 & 6 \\
$2-5$ & 6326 & 55 \\
$6-10$ & 2415 & 21 \\
$>10$ & 2070 & 18 \\
\hline
\end{tabular}

Table 5. Percentage distribution of implant acceptance by clients.

\begin{tabular}{ccc}
\hline Implant & No. & $\%$ \\
\hline Jadelle & 677 & 5.9 \\
Implanon & 121 & 1.1 \\
Total & 798 & 7.0 \\
\hline
\end{tabular}

commonest reason for discontinuation of use [3] [12] [13]. It is highest among those who had bleeding disturbance and it constitute one of the most important side effects? Phase II clinical trials with Nestorone have been completed and bleeding irregularities occurred in $20 \%-30 \%$ of the women but there were only four terminations because of bleeding problems [5] [14].

The pattern of bleeding disturbance (frequency and duration of bleeding) were not found to differ among the two users as compared with a study done in Jos where with respect to bleeding disturbances, frequent bleeding and prolonged bleeding per a 90-day reference period, occurred more among Implanon users, compared to Jadelle users [13] [15]. In this study discontinuation due to menstrual disturbance accounted for 64.8\% for Jadelle and $68.7 \%$ for Implanon.

In a Muslim dominating community reason for this high discontinuation rate is not far-fetched, as Muslim women are not allowed to pray while mensuration or bleeding. The Muslims were found to constitute majority of the client in this study $67.9 \%$ in Table 3 which is almost two third of the population under review. All the respondents were multiparous (see Table 4).

Other reason for discontinuation were mainly desire to be pregnant which was $23 \%$ for Jadelle and $4.3 \%$ for Implanon, which mean that the menstrual disturbance is more severe with those who use Implanon than those with the Jadelle implants. Discontinues rate was found to be $26.6 \%$ for Jadelle and for Implanon was $19.8 \%$ (Table 5 and Table 6).

However, continuation rates for implant use were high among those who have used progesterone-based contraceptives before (such as pill, injectable and even implants). In this center an average of 25\% were found to fall in this category. It was obvious in the results that those who have had other hormonal contraceptive (pills, injectable $30.2 \%$ and implant $27.8 \%$ ) were not discouraged to continue on implants despite the associated presumed side effect. Those who have used hormonal contraceptives (implants and injectable) before were found to be $58 \%$ (see Table 7 ).

Other side effects of implants are similar to those observed with hormonal pills-headache, weight changes, mood swings and abdominal bloating. Studies carried out by the Bangladesh Institute of Research for Promotion of Essential \& Reproductive Health and Technologies, Dhaka shows that after five years of Norplant implant use, there was no clinically significant change in body weight, systolic or diastolic blood pressure that is true in this study.

\section{Conclusions}

A large number of potential implant users were not offered their choice of implants due to its non availability at the time of counseling. This non-availability of the commodity and sometimes lack of medical personnel that is skilled at implant insertion when needed makes it need to be unmet. These challenges are common in some developing countries. Several studies done in and outside the country have also showed that after counseling for 
Table 6. Cumulative percentage of client who discontinue during the first years.

\begin{tabular}{ccccc}
\hline \multirow{2}{*}{ Reason for removal } & \multicolumn{2}{c}{ Jadelle } & \multicolumn{2}{c}{ Implanon } \\
\cline { 2 - 5 } & No. & $\%$ & No. & $\%$ \\
\hline Menstrual problems & 116 & 64.8 & 15 & 68.7 \\
Pregnancy wanted & 20 & 11.2 & 1 & 0.3 \\
Others & 6 & 3.0 & 2 & 2.0 \\
Total & 142 & & 18 & \\
\hline
\end{tabular}

Table 7. Percentage distribution of immediate past contraceptive usage per method mix.

\begin{tabular}{cc|}
\hline Immediate past contraceptive & No. \\
\hline Barrier method & 3.8 \\
Pills & 14.5 \\
Injectable & 30.2 \\
IUCD & 7.4 \\
Implants & 27.8 \\
None & 16.0 \\
\hline
\end{tabular}

family planning method most of the client usually opts for implant however they have to go on long waiting list or choose another method if they have to wait for a long time. It is therefore paramount to say that the true demand for implants is unknown because there are not enough supplies and services available to meet demand. This should also be backed by integration of implants into the national commodity logistics systems to ensure adequate local budgetary provision for contraceptive implant procurement rather than reliance on donor supply. Continuation rates for implant use are high among those who have had adequate pre-insertion counseling because the perceived advantages greatly outweigh the nuisance effects. In this study, the continuation rate was $38 \%$ for Jadelle and 29\% for Implanon. The discontinuation rate was high among those who had menstrual disturbance.

Some of the clients had used hormonal contraceptives and therefore changing to implants as another form of hormonal contraception was not a problem. Over $70 \%$ had one form of educations which means that their level of understanding during counselling must have been good.

Based on the result of these studies, menstrual irregularity (Frequency, duration, and amount) was the principal factors responsible for discontinuation (25\%), which were also the major side effects associated with the use. This is high compared to studies done in other developing countries including Nigeria. In a study done in Jos only four (4) clients discontinued the use of the implant. Attention must be paid to the counselling process in order to reduce the rate of discontinuation.

\section{Acknowledgements}

The Reproductive Health and Family Planning Unit of Ahmadu Bello University Teaching Hospital, ShikaZaria Nigeria service providers is appreciated for experimental contribution. Special recognition is given to Professor Abdul for his professional conduct and also the outstanding effort of the Unit Head to ensure that this study was conducted according to protocol in the field.

\section{Conflict of Interest}

The authors have no conflicts of interest. 


\section{References}

[1] National Population Commission, NDHS (2008) National Population Commission. ORC Marco, Calverton.

[2] Engender Health (2011) SEED Assessment Guide for Family Planning Programming. Engender Health, New York. http://www.engenderhealth.org/pubs/family-planning/seed-assessment-guide-for-family-planning.php

[3] Hubacher, D., Olawo, A., Manduku, C. and Kiarie, J. (2011) Factors Associated with Uptake of Subdermal Contraceptive Implants in a Young Kenyan Population. Contraception, 84, 413-417. http://dx.doi.org/10.1016/j.contraception.2011.02.007

[4] Ladipo, O.A. and Akinso, S.A. (2005) Contraceptive Implants. African Journal of Reproductive Health, 9, 16-30. http://dx.doi.org/10.2307/3583156

[5] Ali, M.M., Cleland, J. and Shah, I.H. (2012) Causes and Consequences of Contraceptive Discontinuation: Evidence from 60 Demographic and Health Surveys. World Health Organization, Geneva.

[6] Darney, P.D. (1994) Hormonal Implants: Contraception for a New Century. America Journal of Obstetrics and Gynecology, 170, 1536. http://dx.doi.org/10.1016/s0002-9378(94)05016-7

[7] (1993) Bangladesh Institute of Research for Promotion of Essential \& Reproductive Health and Technologies, Dhaka, 47, 569-582.

[8] Jacobstein, R. (2009) Fostering Change in Medical Settings: Some Considerations for Family Planning Programmes. IPPF Medical Bulletin, 43, 3-4.

[9] Wickstrom, J. and Jacobstein, R. (2011) Contraceptive Security: Incomplete without Long-Acting and Permanent Methods of Family Planning. Studies in Family Planning, 42, 291-298. http://dx.doi.org/10.1111/j.1728-4465.2011.00292.x

[10] Murthil, J.H. and Nyango, D.D. (2010) East African Medical Journal, 89, 461-464.

[11] http://www.drugs.com/pro/implanon.html

[12] Hubacher, D., Mavranezouli, I. and McGinn, E. (2008) Unintended Pregnancy in Sub-Saharan Africa: Magnitude of the Problem and Potential Role of Contraceptive Implants to Alleviate it. Contraception, 78, 73-78.

[13] Akhter, H., Dunson, T.R., Amatya, R.N., Begum, K., Chowdhury, T., Dighe, N., Krueger, S.L. and Rahman, S. (1993) A Five-Year Clinical Evaluation of Norplant Contraceptive Subdermal Implants in Bangladeshi Acceptors. Contraception, 47, 569-582.

[14] Peralta, O., Diaz, A. and Crozatto (1995) Journal of Steriod Biochemical Molecular Biology, 53.

[15] Chigbu, B., Onwere, S., Aluka, C., Kamanu, C., Okoro, O. and Feyi-Waboso, P. (2010) Contraceptive Choices of Women in Rural Southeastern Nigeria. Nigerian Journal of Clinical Practice, 13, 195-199. 